\title{
Produção de bovinos em pastagens de capim-braquiária diferidas
}

\author{
Manoel Eduardo Rozalino Santos ${ }^{1}$, Dilermando Miranda da Fonseca ${ }^{2}$, Valéria Pacheco Batista \\ Euclides $^{3}$, José Ivo Ribeiro Júnior ${ }^{4}$, Domicio do Nascimento Júnior ${ }^{2}$, Luciano de Melo Moreira ${ }^{5}$ \\ ${ }_{1}^{1}$ Programa de Pós-graduação em Zootecnia - Universidade Federal de Viçosa. Bolsista da CAPES \\ 2 Departamento de Zootecnia - Universidade Federal de Viçosa. \\ 3 Embrapa Gado de Corte. \\ ${ }^{4}$ Departamento de Informática - Universidade Federal de Viçosa. \\ ${ }^{5}$ FEAD-MINAS.
}

\begin{abstract}
RESUMO - Durante os meses de janeiro a setembro de 2004 (ano 1) e de 2005 (ano 2), foram avaliados os efeitos dos períodos de diferimento (ano 1: 103, 121, 146 e 163 dias; ano 2: 73, 103, 131 e 163 dias) e de pastejo (1, 29, 57 e 85 dias) na produção de forragem e no desempenho de bovinos de corte em pastagens diferidas de capim-braquiária (Brachiaria decumbens cv. Basilisk). Adotou-se o delineamento em blocos casualizados, segundo o esquema de parcelas subdivididas, com duas repetições. Houve variação na produção de forragem entre os anos. Pastagens diferidas por maior período possuíram maiores massas de forragem total e forragem morta. Com o aumento do período de pastejo, diminuiram as massas de forragem total e forragem verde e aumentou a massa de forragem morta. A composição química da forragem da amostra de simulação de pastejo foi modificada pelos períodos de diferimento e de pastejo. Não houve efeito dos períodos de diferimento e de pastejo sobre o consumo do suplemento, expresso em porcentagem do peso corporal. O desempenho dos bovinos diminuiu durante o período de pastejo no ano 1 (de 0,739 para 0,467 kg/animal.dia) e no ano 2 (de 0,885 para 0,189 kg/animal.dia) e foi maior em pastagens diferidas por menor período no ano 2 (0,692 kg/animal.dia). O ganho de peso por área foi maior em pastagens diferidas por menor período no ano 2 (4,87 kg/ha.dia). Na região de Viçosa, a produção de bovinos em recria em pastagens diferidas melhora quando o pasto adubado e suplementado de Brachiaria decumbens cv. Basilisk é diferido por cerca de 70 dias e utilizado a partir do início do mês de julho.
\end{abstract}

Palavras-chave: Brachiaria decumbens, massa de forragem, período de diferimento, período de pastejo, suplementação

\section{Bovine production on deferred signalgrass pastures}

\begin{abstract}
Throughout January to September 2004 (first year) and 2005 (second year), the effects of 103, 121, 146 and 163-day (first year), and 73, 103, 131 and 163-day (second year) deferring periods, as well as 1, 29, 57 and 85-day grazing on forage production and beef cattle performance in Brachiaria decumbens cv. Basilisk were evaluated. Randomized block design with two replicates, according to the subdivided plots scheme was used. Variation in forage production between the first and second year was observed. Pastures deferred for a longer period had higher total forage mass and dead forage. As the grazing period increased, the total and green forage mass decreased, and the dead forage mass increased. The chemical composition of the forage sample from the grazing simulation was modified by the deferring and grazing periods. The deferring and grazing periods did not affect the supplement intake, expressed as body weight percentage. The bovine performance diminished during the grazing period in the first year (from 0.739 to $0.467 \mathrm{~kg} / \mathrm{animal} . \mathrm{day}$ ) and in the second year (from 0.885 to $0.189 \mathrm{~kg} / \mathrm{animal}$.day). Pastures deferred for shorter periods in the second year showed higher performance (0.692 kg/animal.day). The weight gain by area was higher on pastures deferred for shorter periods in the second year $(4.87 \mathrm{~kg} / \mathrm{ha}$.day). In the region of Viçosa, the growing cattle production, kept in deferred pastures, is maximized when pasture fertilized and supplemented by Brachiaria decumbens cv. Basilisk is deferred for about 70 days and used from early July on.
\end{abstract}

Key Words: Brachiaria decumbens, deferring period, forage mass, grazing period, supplementation

\section{Introdução}

A importância das pastagens na produção de bovinos no Brasil é inquestionável e reconhecida, fato relacionado, entre outros fatores, ao baixo custo de produção nestas condições. Todavia, em razão da fenologia das forrageiras tropicais e das condições de clima no decorrer do ano, a produção de forragem nas áreas de pastagens é estacional, o que resulta na sazonalidade da produção animal. 
Existem estratégias para disponibilizar forragem suplementar durante o período crítico do ano em recurso forrageiro, como: formação de capineiras de capim ou de cana-de-açúcar, ensilagem, fenação e diferimento do uso da pastagem. Estas estratégias são viáveis tecnicamente, porém o diferimento do uso da pastagem consiste em uma das estratégias de mais fácil adoção e, em geral, de menor custo.

Bovinos mantidos em pastagens diferidas expressam desempenho modesto ou simplesmente mantêm seu peso corporal (Santos et al., 2004; Gomes Jr. et al., 2002), pois a forragem diferida é, geralmente, de baixa qualidade. Assim, quando se almeja maior desempenho animal, pode-se adotar a estratégia de suplementação do pasto diferido para complementar o valor nutritivo da forragem disponível e/ou melhorar a conversão alimentar (Euclides \& Medeiros, 2005).

Para otimizar a suplementação em pastagens diferidas, a disponibilidade de forragem não deve ser limitante ao consumo animal. Nesse sentido, o período em que o pasto permanece diferido é fundamental para garantir produção de forragem em quantidade e qualidade. Pastagens diferidas por longo período possuem alta produção de forragem, porém de pior valor nutritivo. Por outro lado, menor período de diferimento pode determinar baixa produção de forragem.

Além disso, durante o período de pastejo ocorrem modificações na massa e na oferta de forragem disponível, o que afeta o comportamento ingestivo e o desempenho dos animais, mesmo quando estes consomem suplemento.

A compreensão dos efeitos dos períodos de diferimento e de pastejo sobre a massa de forragem da pastagem e o desempenho animal pode resultar na geração de recomendações eficientes de manejo em pastagens diferidas. Assim, realizou-se este trabalho com o objetivo de avaliar a produção de forragem e a produtividade animal em pastagens de Brachiaria decumbens cv. Basilisk (Stapt.) diferidas.

\section{Material e Métodos}

Dois ensaios foram realizados em área de pastagem de Brachiaria decumbens cv. Basilisk (Stapt.), no Setor Forragicultura do Departamento de Zootecnia da Universidade Federal de Viçosa (UFV), localizado em Viçosa, Minas

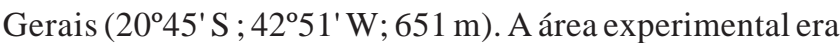
constituída de oito piquetes de 0,25 a 0,40 ha. O primeiro ensaio foi realizado de janeiro a setembro de 2004 e foi denominado ano 1 e o segundo, de janeiro a setembro de 2005 e foi denominado ano 2. Durante o período de avaliação, foram registrados os dados climáticos na área experimental (Tabela 1).
Tabela 1 - Médias mensais da temperatura média diária, precipitação pluvial e insolação durante os períodos de janeiro a setembro de 2004 (ano 1) e janeiro a setembro de 2005 (ano 2)

\begin{tabular}{|c|c|c|c|c|c|c|}
\hline \multirow[t]{2}{*}{ Mês } & \multicolumn{2}{|c|}{$\begin{array}{c}\text { Temperatura } \\
\left({ }^{\circ} \mathrm{C}\right)\end{array}$} & \multicolumn{2}{|c|}{$\begin{array}{c}\text { Precipitação } \\
(\mathrm{mm})\end{array}$} & \multicolumn{2}{|c|}{$\begin{array}{l}\text { Insolação } \\
\text { (horas/dia) }\end{array}$} \\
\hline & Ano 1 & Ano 2 & Ano 1 & Ano 2 & Ano 1 & Ano 2 \\
\hline Janeiro & 22,1 & 22,7 & 405,9 & 203,1 & - & 4,3 \\
\hline Fevereiro & 22,0 & 22,2 & 357,4 & 200,2 & 3,2 & 6,3 \\
\hline Março & 21,5 & 22,6 & 205,4 & 267,5 & 6,0 & 5,2 \\
\hline Abril & 20,8 & 21,4 & 136,7 & 57,6 & 5,5 & 6,0 \\
\hline Maio & 18,1 & 18,7 & 41,6 & 45,0 & 4,5 & 6,0 \\
\hline Junho & 15,8 & 17,0 & 40,7 & 32,7 & 4,9 & 4,9 \\
\hline Julho & 15,7 & 15,8 & 35,6 & 24,5 & 5,5 & 6,0 \\
\hline Agosto & 16,7 & 17,9 & 0,2 & 37,4 & 7,3 & 6,7 \\
\hline Setembro & 19,8 & 19,6 & 0,0 & 67,5 & 7,5 & 3,2 \\
\hline
\end{tabular}

Os tratamentos consistiram de combinações entre períodos de diferimento da pastagem, casualizados às parcelas, e períodos de pastejo, casualizados nas subparcelas. As subparcelas consistiram de medidas ao longo do período de pastejo (1, 29, 57 ou 85 dias), dentro de cada período de diferimento (103, 121, 146 e 163 dias no ano 1; e 73, 103, 131 e 163 dias no ano 2). Foi utilizado o delineamento em blocos casualizados, em esquema de parcelas subdivididas, com duas repetições. Os piquetes foram diferidos em diferentes datas, pois o pastejo iniciou-se na mesma data (sete de julho) em ambos os experimentos.

O solo da área experimental é um Latossolo VermelhoAmarelo, de textura argilosa e com relevo medianamente ondulado. No dia 17 de dezembro de 2003, realizou-se a amostragem de solo, na camada $0-20 \mathrm{~cm}$, cujos resultados da análise química foram: $\mathrm{pH}$ em $\mathrm{H}_{2} \mathrm{O}: 5,0 ; \mathrm{P}: 2,44$ (Mehlich-1) e $\mathrm{K}: 98,13 \mathrm{mg} / \mathrm{dm}^{3} ; \mathrm{Ca}^{+2}: 2,45 ; \mathrm{Mg}^{+2}: 0,56$ e $\mathrm{Al}^{+3}$ : $0,16 \mathrm{cmol}_{\mathrm{C}} / \mathrm{dm}^{3}(\mathrm{KCl} 1 \mathrm{~mol} / \mathrm{L})$. Com base nesses resultados, não foi feita a calagem. Aplicaram-se $50 \mathrm{~kg} / \mathrm{ha}$ de $\mathrm{P}_{2} \mathrm{O}_{5}$, na forma de superfosfato simples, no dia 6 de janeiro de 2004. A adubação potássica, na forma de cloreto de potássio, para aumentar a disponibilidade de potássio para $150 \mathrm{mg} / \mathrm{dm}^{3}$, foi realizada juntamente com a adubação nitrogenada, nas datas de início do diferimento, quando $70 \mathrm{~kg} / \mathrm{ha}$ de nitrogênio, na forma de uréia, foram aplicados em cada piquete. No ano 2, foi realizada apenas a adubação nitrogenada nas datas de início do diferimento, de forma semelhante à do ano 1.

No período de dezembro de 2003 até as datas de início do diferimento no ano 1 e de novembro de 2004 até as datas de início de diferimento no ano 2, todos os piquetes foram manejados para manter as alturas dos pastos em aproximadamente $20 \mathrm{~cm}$. Para isso, adotou-se o método de pastejo em lotação contínua, com taxa de lotação variável. Os piquetes foram mantidos diferidos até o dia 7 de julho, 
quando se iniciou o período de pastejo. Todas as pastagens foram manejadas sob lotação contínua com taxa de lotação fixa.

Foram utilizados, em cada ano, 17 bovinos machos, não-castrados, mestiços, com peso médio inicial de $190 \mathrm{~kg}$. Antes do período de utilização das pastagens diferidas, os animais foram adaptados ao consumo de suplemento concentrado durante 20 dias. A distribuição dos animais nos piquetes foi feita de forma sistemática para manter a taxa de lotação inicial de aproximadamente $3 \mathrm{UA} / \mathrm{ha}$ em todos os piquetes, mantendo-se mínimo de dois animais por unidade experimental.

Todos os piquetes eram providos de cochos de madeira para o fornecimento do suplemento concentrado, bem como de bebedouros. Durante todo período de pastejo, os animais tiveram acesso ao suplemento concentrado, composto de: $74,7 \%$ de fubá de milho, $10 \%$ de uréia, 0,3\% de enxofre, $5 \%$ de fosfato bicálcico e $10 \%$ de mistura mineral. Diariamente, uma quantidade de suplemento foi colocada nos cochos de cada piquete, de forma a não limitar o consumo pelos animais. Antes do fornecimento diário, as sobras do do suplemento, em cada piquete, referentes à quantidade não consumida no dia anterior, também foram recolhidas e pesadas. Pela diferença entre o peso de suplemento ofertado e o peso de suas sobras, foi estimado o consumo diário de suplemento em cada piquete, que foi dividido pelo número de animais por piquete para estimativa do consumo médio diário de suplemento por animal (kg/animal.dia). O consumo de suplemento também foi expresso em porcentagem do peso animal. Para isso, a quantidade diária de suplemento consumida foi divida pelo peso médio dos animais e, depois, multiplicada por 100.

Os animais foram pesados, sem e com jejum de 15 horas, no primeiro e no último dia do período de pastejo. Durante o período de utilização das pastagens diferidas, todos os animais foram pesados a cada 28 dias, sem jejum prévio e pela manhã.

A taxa de lotação foi calculada, de forma pontual, em cada dia de pesagem dos animais, dividindo-se o somatório do peso dos animais em cada piquete pela respectiva área do piquete. Os valores foram expressos em unidade animal (UA)/ha, de modo que uma unidade animal correspondeu a $450 \mathrm{~kg}$ de peso corporal. O ganho de peso médio diário (kg/animal.dia) foi obtido pela diferença de peso dos animais entre duas pesagens consecutivas, dividida pelo número de dias entre estas pesagens. O ganho de peso médio diário por unidade de área ( $\mathrm{kg} / \mathrm{ha}$.dia) foi calculado pelo quociente entre o ganho de peso acumulado dos animais presentes em cada piquete pela respectiva área da unidade experimental; em seguida, esse resultado foi dividido pelo período de avaliação.
No ano 2, foi colhida uma amostra de forragem simulando o pastejo em cada piquete no $1^{\circ}$, $29^{\circ}$, $57^{\circ} \underline{0}$ e $85^{\circ}$ dias do período de pastejo. Cada amostra foi separada nos componentes morfológicos lâmina foliar verde, colmo verde, lâmina foliar morta e colmo morto. As amostras de simulação de pastejo tiveram seus teores de matéria seca (MS), fibra em detergente neutro (FDN) e compostos nitrogenados totais (PB) determinados de acordo com as técnicas descritas por Silva \& Queiroz (2002). A fibra em detergente neutro indigestível (FDNi) foi estimada pela digestibilidade in situ, por 240 horas. A fibra em detergente neutro potencialmente digestível (FDNpoD) e a matéria seca potencialmente digestível (MSpoD) foram calculadas de acordo com Paulino et al. (2006).

Nos dois anos de pesquisa, amostragens da massa de forragem foram realizadas desde o primeiro dia, a intervalos de 28 dias, até o último dia do período de pastejo. Em três áreas representativas da condição média do pasto em cada piquete, foi realizado o corte, no nível solo, de todos os perfilhos contidos no interior de um quadrado de $0,25 \mathrm{~m}^{2}$ de área, constituindo-se uma amostra. Cada amostra foi acondicionada em saco plástico identificado e, no laboratório, foi pesada e subdividida em duas partes. Uma das subamostras foi pesada, acondicionada em saco de papel e colocada em estufa com ventilação forçada, a $65^{\circ} \mathrm{C}$, durante 72 horas, quando novamente foi pesada. A outra subamostra foi separada manualmente em forragem verde e morta. As partes do colmo e da lâmina foliar com amarelecimento e/ou necrosamento do órgão foram incorporadas à forragem morta. Após a separação, os componentes foram pesados e secos em estufa de circulação forçada de ar a $65^{\circ} \mathrm{C}$, por 72 horas. A partir desses dados, estimaram-se as massas de forragem total, verde e morta por unidade de área.

Em cada piquete, as ofertas de forragem total, forragem verde e forragem morta foram calculadas, de forma pontual, durante o período de pastejo pela divisão das massas de forragem $(\mathrm{kg} / \mathrm{ha})$ pelo peso animal ( $\mathrm{kg} / \mathrm{ha})$.

As análises dos dados experimentais foram feitas usando o Sistema para Análises Estatísticas - SAEG, versão 8.1 (UFV, 2003). Para cada característica, foram realizadas análises de variância e, posteriormente, análises de regressão, cujo maior modelo de superfície de resposta nas médias dos tratamentos foi o seguinte:

$$
Y_{i}=\beta_{0}+\beta_{1} D_{i}+\beta_{2} P_{i}+\beta_{3} D_{i} P_{i}+e_{i}
$$

em que: $Y_{i}=$ variável-resposta; $D_{i}=$ período de diferimento; $\mathrm{P}_{\mathrm{i}}=$ período de pastejo; $\beta_{0}, \beta_{1}, \beta_{2}, \beta_{3}=$ parâmetros a ser estimados; $\mathrm{e}_{\mathrm{i}}=$ erro experimental.

O grau de ajustamento dos modelos foi avaliado pelo coeficiente de determinação e pela significância dos 
coeficientes de regressão, testada pelo teste t corrigido com base nos resíduos da análise de variância. Foram calculados os coeficientes de variação referentes à parcela (CV a) e à subparcela (CV b) para cada variável resposta. As equações de regressão para o desempenho animal em função das características do pasto diferido também foram ajustadas. Para isso, avaliou-se o coeficiente de determinação e a significância dos coeficientes de regressão, testada pelo teste t. Os coeficientes de correlação linear simples entre algumas variáveis foram estimados e seus valores testados pelo teste t. Todas as análises estatísticas foram realizadas ao nível de significância de até $10 \%$ de probabilidade.

\section{Resultados e Discussão}

Os períodos de diferimento e de pastejo influenciaram as massas de forragem das pastagens diferidas (Tabela 2). No ano 2, a massa de forragem total (FT) aumentou linearmente $(\mathrm{P}<0,01)$ com o período de diferimento e diminuiu $(\mathrm{P}<0,01)$ com o período de pastejo. No ano 1 , houve efeito da interação $(\mathrm{P}<0,05)$ entre períodos de diferimento e de pastejo no comportamento desta variável. A massa de forragem verde $(\mathrm{FV})$ foi influenciada $(\mathrm{P}<0,01)$ apenas pelo período de pastejo, de forma linear e negativa nos dois anos de avaliação. A massa de forragem morta (FM) elevou, segundo o modelo linear, conforme aumentaram os períodos de diferimento $(\mathrm{P}<0,01)$ e de pastejo no ano $1(\mathrm{P}<0,01)$ e no ano $2(\mathrm{P}<0,10)$.

No ano 1 , houve efeito de interação $(\mathrm{P}<0,05)$ entre períodos de diferimento e de pastejo para a massa de forragem total, que, no primeiro dia de pastejo, foi maior nas pastagens diferidas por maior período, comportamento esperado. Entretanto, no último dia de pastejo, praticamente não houve diferença na massa de forragem total entre as pastagens entre períodos de diferimento, o que pode ter sido resultado das maiores perdas de forragem durante o pastejo nos pastos diferidos por período mais longo. Nestes pastos, os perfilhos encontravam-se tombados, o que proporcionou maior impacto do pisoteio animal sobre as plantas durante o pastejo. Por outro lado, as pastagens diferidas por menor período, possuíam estrutura de pasto menos predisponentes às perdas de forragem durante o pastejo. Provavelmente, o efeito de interação entre períodos de diferimento e de pastejo para a massa de forragem total não ocorreu $(\mathrm{P}>0,10)$ no ano 2 , em virtude da menor produção de forragem nesse ano em comparação ao ano 1. Portanto, quanto menor a massa de forragem total em pastagens diferidas de capim-braquiária, menor a possibilidade de ocorrência de perdas de forragem durante o pastejo.

A massa de forragem verde não foi influenciada $(\mathrm{P}>0,10)$ pelo período de diferimento. Pastagens diferidas por maior período possuíam menor percentual de forragem verde, porém elevada massa de forragem total. Como consequência, a massa de forragem verde também foi alta nestas pastagens. Em contrapartida, pastagens diferidas por menor período possuíram menor massa de forragem total. No entanto, esta massa foi caracterizada por elevado percentual de forragem verde, o que resultou em massa de forragem verde similar àquela verificada em pastos diferidos por maior período.

Pastagens diferidas por maior período foram caracterizadas por maior massa de forragem morta, como resultado da intensificação do processo de senescência, comum durante o desenvolvimento de pastos mantidos por longo período de rebrotação. De acordo com Parsons et al. (1983), longos períodos de crescimento comprometem a produção líquida de forragem, por intensificarem tanto as perdas por senescência quanto as perdas respiratórias de carbono.

Tabela 2 - Estimativas das massas de forragem total, verde e morta em pastos de capim-braquiária diferidos

\begin{tabular}{|c|c|c|c|c|}
\hline Massa de forragem & Equação & $r^{2}(\%)$ & $\mathrm{CV} \mathrm{a}^{1}(\%)$ & $\mathrm{CV} \mathrm{b}^{2}(\%)$ \\
\hline \multicolumn{5}{|c|}{ Ano 1} \\
\hline Forragem total & $\hat{Y}=3613,24+66,496 D+88,976^{+} P-0,93735 * D P$ & 0,47 & 37,07 & 11,92 \\
\hline Forragem verde & $\hat{\mathrm{Y}}=7968,42-58,3597 * * \mathrm{P}$ & 0,67 & 60,62 & 29,19 \\
\hline Forragem morta & $\hat{\mathrm{Y}}=-1125,67+42,2592 * * \mathrm{D}+22,4338 * * \mathrm{P}$ & 0,77 & 14,63 & 23,62 \\
\hline \multicolumn{5}{|c|}{ Ano 2} \\
\hline Forragem total & $\hat{\mathrm{Y}}=4812,33+28,3184 * * \mathrm{D}-33,6267 * * \mathrm{P}$ & 0,76 & 9,75 & 18,87 \\
\hline Forragem verde & $\hat{\mathrm{Y}}=5127,78-42,1624 * * \mathrm{P}$ & 0,79 & 11,74 & 30,70 \\
\hline Forragem morta & $\hat{\mathrm{Y}}=948,54+33,7294 * * \mathrm{D}+8,5357^{+} \mathrm{P}$ & 0,83 & 14,50 & 21,93 \\
\hline
\end{tabular}

${ }^{1}$ Coeficiente de variação do fator período de diferimento; ${ }^{2}$ Coeficiente de variação do fator período de pastejo; ** Significativo pelo teste $\mathrm{t}(\mathrm{P}<0,01)$; * Significativo pelo teste $\mathrm{t}(\mathrm{P}<0,05) ;{ }^{+}$Significativo pelo teste $\mathrm{t}(\mathrm{P}<0,10) ; \mathrm{D}=$ períodos de diferimento; $\mathrm{P}=$ períodos de pastejo. 
Durante o período de pastejo, no inverno, as condições climáticas foram desfavoráveis ao crescimento do capimbraquiária. Dessa forma, é provável que tenha ocorrido acúmulo negativo de forragem (taxas de senescência maiores que as taxas de crescimento vegetal) nessa época, o que explicaria a redução das massas de forragem total e, principalmente, forragem verde durante a utilização das pastagens diferidas, da mesma forma que a elevação da massa de forragem morta. O pastejo seletivo dos bovinos é outro fator que contribuiu significativamente para a redução da massa de forragem verde durante a utilização dos pastos diferidos, uma vez que estes animais consomem preferencialmente as partes verdes da forrageira (Carvalho et al., 2001).

Os períodos de diferimento e de pastejo afetaram a oferta de forragem em pastagens diferidas (Tabela 3 ). No ano 1 , houve efeito da interação $(\mathrm{P}<0,01)$ entre os fatores estudados para a oferta de forragem total. No ano 2 , maior período de diferimento aumentou $(\mathrm{P}<0,05)$ e o período de pastejo diminuiu $(\mathrm{P}<0,01)$ a oferta de forragem total. Em ambos os anos, a oferta de forragem verde decresceu ( $\mathrm{P}<0,01)$ com o maior período de pastejo. O maior período de diferimento resultou em maior oferta de forragem morta no ano $1(\mathrm{P}<0,01)$ e no ano $2(\mathrm{P}<0,05)$.

A variação nas ofertas de forragens com o período de diferimento pode ser justificada pela análise das estimativas das massas de forragem total, verde e morta nas pastagens diferidas (Tabela 2), uma vez que o peso animal por unidade de área foi similar em todas as unidades experimentais no início do experimento. Durante o período de pastejo, ocorreu redução nas massas de forragem total e forragem verde, bem como aumento na massa de forragem morta. Como os animais ganharam peso neste período, o peso animal por área também aumentou, o que determinou diminuição das ofertas de forragem total e verde e ausência de efeito sobre a oferta de forragem morta com o aumento do período de pastejo. No ano 1, pastagens diferidas por 103, 121, 146 e 163 dias resultaram em oferta média de forragem total durante o período de pastejo correspondente a 6,65; 5,98; 6,47 e 7,65 kg de MS de forragem por kg de peso corporal, respectivamente. No ano 2, os valores foram de 3,46; 3,75; 4,41 e 5,23 kg de MS de forragem por kg de peso corporal para as pastagens diferidas por 73, 103, 131 e 163 dias, respectivamente. Esses valores de oferta de forragem total são bastantes elevados e são necessários para evitar a redução no desempenho animal por baixo valor nutritivo da forragem. De fato, quanto melhor a qualidade da forragem, maiores os ganhos de peso por animal e menor a oferta de forragem necessária para isso (Euclides, 2001). Todavia, de acordo com Santos et al. (2004), em situações de baixa ingestão de matéria seca e elevada oferta de forragem, o aumento na oferta de forragem pode não alterar necessariamente o consumo de forragem e o desempenho animal, uma vez que o animal pode não conseguir utilizar essa forragem.

Muitos trabalhos com forrageiras tropicais têm comprovado que a produção animal não está relacionada ao total de forragem disponível, mas à disponibilidade de forragem verde (Euclides \& Euclides Filho, 1997). Assim torna-se relevante expressar a oferta de forragem com base na massa de forragem verde. No ano 1 , pastagens diferidas por 103, 121, 146 e 163 dias foram caracterizadas por oferta média de forragem verde durante todo o período de pastejo correspondente a 4,14; 2,99; 2,94 e 3,52 kg de MS de forragem por kg de peso corporal, respectivamente. No ano 2, os valores foram de 2,11; 2,35; 1,92 e 2,03 kg de MS de forragem por kg de peso corporal nas pastagens diferidas por 73, 103, 131 e 163 dias, respectivamente.

Em decorrência da alta disponibilidade de forragem nas pastagens diferidas, adotou-se taxa de lotação (TL) inicial de aproximadamente 3,00 UA/ha. A manutenção dessa taxa de lotação também foi possível com a suplementação dos

Tabela 3 - Estimativas das ofertas de forragem total, verde e morta em pastagens de capim-braquiária diferidas

\begin{tabular}{|c|c|c|c|c|}
\hline Oferta de forragem ${ }^{1}$ & Equação & $\mathrm{R}^{2}(\%)$ & $\mathrm{CV} \mathrm{a}(\%)$ & $\mathrm{CV} \mathrm{b}^{3}(\%)$ \\
\hline Forragem total & $\hat{\mathrm{Y}}=2,4026+0,04587 \mathrm{D}+0,04698^{+} \mathrm{P}-0,000668 * * \mathrm{DP}$ & 0,64 & 29,58 & 10,88 \\
\hline Forragem verde & $\hat{\mathrm{Y}}=5,3847-0,0456896 * * \mathrm{P}$ & 0,73 & 55,68 & 22,34 \\
\hline Forragem morta & $\hat{\mathrm{Y}}=-0,204057+0,026213 * * \mathrm{D}$ & 0,62 & 5,32 & 24,37 \\
\hline \multicolumn{5}{|c|}{ Ano 2} \\
\hline Forragem total & $\hat{\mathrm{Y}}=3,23242+0,0201425 * \mathrm{D}-0,0313267 * * \mathrm{P}$ & 0,81 & 20,28 & 18,22 \\
\hline Forragem verde & $\hat{\mathrm{Y}}=3,53911-0,0324998 * * \mathrm{P}$ & 0,83 & 35,74 & 22,21 \\
\hline Forragem morta & $\hat{\mathrm{Y}}=-0,529135+0,0224848 * \mathrm{D}$ & 0,80 & 38,96 & 20,27 \\
\hline
\end{tabular}

1 em kg de matéria seca de forragem por kg de peso corporal; ${ }^{2}$ Coeficiente de variação do fator período de diferimento; ${ }^{3}$ Coeficiente de variação do fator período de pastejo ** Significativo pelo teste t $(\mathrm{P}<0,01)$; * Significativo pelo teste t $(\mathrm{P}<0,05) ;{ }^{+}$Significativo pelo teste $\mathrm{t}(\mathrm{P}<0,10)$; $\mathrm{D}=$ períodos de diferimento; $\mathrm{P}=$ períodos de pastejo. 
pastos diferidos. Provavelmente, neste experimento, ocorreu efeito substitutivo da forragem diferida pelo suplemento utilizado, principalmente ao término do período de pastejo. Euclides et al. (1998) também verificaram que, durante o período seco, os piquetes de Brachiaria decumbens onde os animais tiveram acesso ao suplemento apresentaram maior capacidade de suporte que aqueles em que os animais não consumiram suplemento. Como esperado, a taxa de lotação aumentou $(\mathrm{P}<0,01)$ de forma linear durante o período de pastejo porque os animais ganharam peso durante esse período (Tabela 5).

Os efeitos dos períodos de diferimento e de pastejo foram lineares para todas as características referentes à composição bromatológica da amostra de forragem obtida pela simulação de pastejo no ano 2 (Tabela 4). Os teores de $\mathrm{PB}(\mathrm{P}<0,01)$ e FDN $(\mathrm{P}<0,05)$ e MS potencialmente digestíveis $(\mathrm{P}<0,05)$ diminuíram com os períodos de diferimento e de pastejo, contrariamente aos teores de FDN $(\mathrm{P}<0,10)$ e FDNi $(\mathrm{P}<0,05)$. Esse padrão de resposta é conseqüência das variações na composição morfológica da forragem das amostras de pastejo simulado. Maiores períodos de diferimento e de pastejo resultaram em maior percentual de colmos mortos e menor percentual de lâminas foliares verdes. Assim, os percentuais de $\mathrm{PB}(\mathrm{r}=0,63)$ e FDN $(\mathrm{r}=0,84)$ e MS potencialmente digestíveis $(r=0,92)$ foram correlacionados $(\mathrm{P}<0,01)$ positivamente com percentual de lâminas foliares verdes da amostra de pastejo simulado, e os teores de FDN $(r=0,61)$ e FDNi $(r=0,94)$ correlacionaram-se positivamente $(\mathrm{P}<0,01)$ com o percentual de colmos mortos da amostra de pastejo simulado. A causa destas correlações se deve à composição química específica de cada componente morfológico da forragem.

O valor nutritivo inferior da forragem obtida pela simulação de pastejo animal naquelas pastagens diferidas por maior período e sob maior período de pastejo indica que a forragem ingerida pelos bovinos era de baixo valor nutricional. Isso pode explicar o menor desempenho animal obtido em pastos submetidos a maiores períodos de diferimento e de pastejo (Tabela 5), mesmo quando suplementados.

Durante o período de pastejo, a forragem da amostra de pastejo simulado possuiu teor médio de PB de 8,07\%. Considerando que a forragem obtida pela simulação de pastejo assemelha-se à forragem selecionada pelos bovinos (Euclides et al., 1992; Moraes et al., 2005), o teor de nitrogênio não foi fator limitante na forragem selecionada pelos animais, já que a exigência de compostos nitrogenados dos microrganismos ruminais deixa de ser atendida apenas em níveis dietéticos basais de proteína bruta inferior a 7\% (Van Soest, 1994). Por outro lado, a garantia teórica de que toda a extensão da FDN potencialmente digestível possa ser utilizada pelos microrganismos ao serem supridos níveis mínimos de 7\% de PB não assegura sua otimização, uma vez que estímulos sobre a taxa de digestão ainda são verificados com a elevação dos níveis de proteína a valores próximos de 13-14\% (Lazzarini et al., 2006). Dessa forma, neste estudo, o consumo de forragem com características semelhantes àquela colhida na simulação do pastejo animal não asseguraria a otimização da digestão da FDN potencialmente digestível . Para isso, o fornecimento de suplementos que permitam elevar o teor de PB da dieta constitui-se em estratégia de manejo apropriada.

Não houve efeito $(\mathrm{P}>0,10)$ dos períodos de diferimento e de pastejo sobre o consumo de suplemento, calculado em porcentagem do peso corporal (Tabela 5). No ano 1, o consumo de suplemento médio foi de $0,39 \%$ do peso animal e, no ano 2, 0,26\% do peso animal. Pode ser que o nível de uréia utilizado no suplemento (10\%) tenha controlado seu consumo a um valor limite, que foi alcançado independentemente do período de diferimento dos pastos. A quantidade diária de suplemento consumida por animal aumentou no decorrer do período de utilização das pastagens diferidas. Como o peso corporal dos animais também aumentou durante o período de pastejo, o consumo diário de suple-

Tabela 4 - Estimativa da composição bromatológica da forragem obtida por meio da simulação de pastejo em pastagens de capim-braquiária diferidas

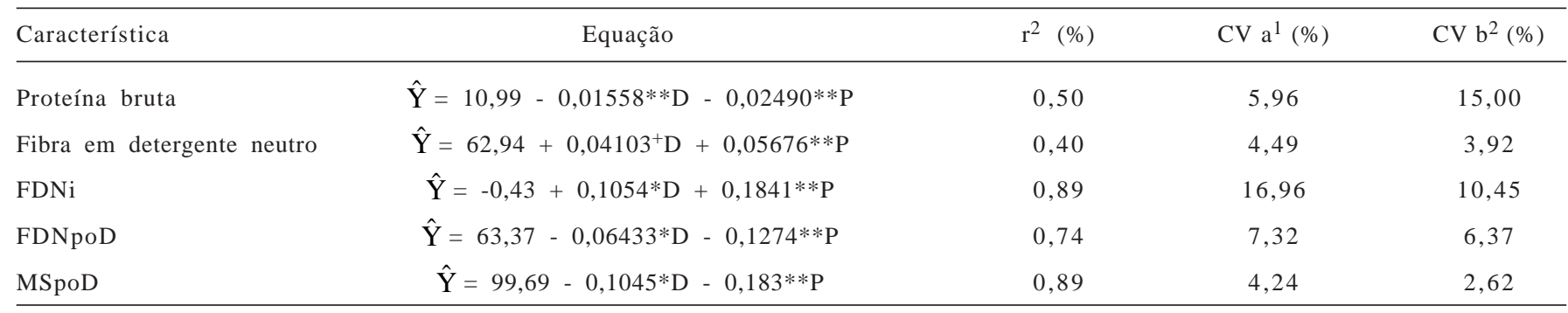

FDNi - fibra em detergente neutro indigestível; FDNpoD - fibra em detergente neutro potencialmente digestível; MSpoD - matéria seca potencialmente digestível;

${ }^{1}$ Coeficiente de variação do fator período de diferimento; ${ }^{2}$ Coeficiente de variação do fator período de pastejo; ** Significativo pelo teste $\mathrm{t}(\mathrm{P}<0,01)$; * Significativo pelo teste $\mathrm{t}(\mathrm{P}<0,05)$; ${ }^{+}$Significativo pelo teste $\mathrm{t}(\mathrm{P}<0,10) ; \mathrm{D}=$ períodos de diferimento; $\mathrm{P}=$ períodos de pastejo. 
Tabela 5 - Estimativas do consumo de suplemento em porcentagem do peso corporal, da taxa de lotação, do ganho de peso por animal e por área em pastagens de capim-braquiária diferidas

\begin{tabular}{|c|c|c|c|c|}
\hline Oferta deforragem & Equação & $r^{2}(\%)$ & $\mathrm{CV} \mathrm{a}{ }^{1}(\%)$ & $\mathrm{CV} \mathrm{b}^{2}(\%)$ \\
\hline Consumo de suplemento ( $\%$ do peso corporal) & $\hat{\mathrm{Y}}=0,39$ & - & 36,06 & 9,98 \\
\hline Ganho de peso por animal (kg/animal.dia) & $\hat{\mathrm{Y}}=0,8925-0,0048^{* *} \mathrm{P}$ & 0,64 & 44,81 & 17,26 \\
\hline Ganho de peso por área (kg/ha.dia) & $\hat{\mathrm{Y}}=6,7661-0,0367 * * \mathrm{P}$ & 0,72 & 45,59 & 19,01 \\
\hline Consumo de suplemento (\%) & $\hat{\mathrm{Y}}=0,26$ & - & 91,11 & 16,69 \\
\hline Taxa de lotação (UA/ha) & $\hat{\mathrm{Y}}=3,1305+0,0083 * * \mathrm{P}$ & 0,66 & 8,82 & 1,08 \\
\hline Ganho de peso (kg/animal.dia) & $\hat{Y}=1,5878-0,002943^{+} \mathrm{D}-0,01215^{* *} \mathrm{P}$ & 0,84 & 36,59 & 25,49 \\
\hline Ganho de peso por área (kg/ha.dia) & $\hat{\mathrm{Y}}=11,9969-0,02240^{+} \mathrm{D}-0,9144^{* *} \mathrm{P}$ & 0,82 & 33,18 & 26,40 \\
\hline
\end{tabular}

${ }^{1}$ Coeficiente de variação do fator período de diferimento; ${ }^{2}$ Coeficiente de variação do fator período de pastejo; ** Significativo pelo teste $\mathrm{t}(\mathrm{P}<0,01) ;{ }^{+}$Significativo pelo teste $\mathrm{t}(\mathrm{P}<0,10)$; $\mathrm{D}=$ períodos de diferimento; $\mathrm{P}=$ períodos de pastejo.

mento, expresso em percentual do peso animal, permaneceu inalterado. No ano 1, a média de consumo de suplemento durante todo o período de pastejo foi de 893 g/animal.dia, superior à verificada no ano 2 , que correspondeu a 600 g/animal.dia. É provável que o maior consumo de suplemento no ano 1 esteja relacionado à genética dos animais utilizados, que eram mestiços de origem leiteira e com menor grau de sangue zebuíno em comparação aos animais avaliados no ano 2 .

No ano 1 , o ganho de peso médio diário dos animais (GPD) reduziu $(\mathrm{P}<0,01)$ linearmente durante o período de pastejo. No ano 2, foi influenciado de forma linear e negativa pelos períodos de diferimento $(\mathrm{P}<0,10)$ e de pastejo $(\mathrm{P}<0,01)$ (Tabela 5). O ganho de peso diário não foi influenciado $(\mathrm{P}>0,10)$ pelo período de diferimento no ano 1 , provavelmente em razão da inexistência de efeito deste fator sobre a massa de FV nas pastagens diferidas, característica intimamente correlacionada ao desempenho de bovinos em pastagens. Além disso, neste ano o consumo de suplemento foi maior, o que pode ter ocultado o efeito da forragem diferida sobre o desempenho animal. O efeito do período de pastejo sobre o GPD foi mais acentuado, que o efeito do período de diferimento. Pode-se afirmar que durante o período de pastejo as alterações na estrutura do pasto foram mais intensas, em virtude da influência do animal, com seu pastejo seletivo, e do processo de senescência, comum no inverno. Todos esses fatores resultaram em menor massa de forragem, com maior proporção de material morto. Vários pesquisadores relatam que o consumo máximo em pastagens pode ser limitado quando o pasto possui alto percentual de material morto, mesmo quando a disponibilidade de matéria seca é alta (Euclides et al., 1990). Assim, os pastos diferidos por maior período e submetidos a longos períodos de pastejo foram caracterizados por uma estrutura não predisponente ao consumo e, como consequência, resultaram em menor desempenho animal.

Neste experimento, não foram obtidos modelos adequados para descrever o desempenho animal na massa de forragem total presente nas pastagens diferidas. A determinação da massa de forragem total é insuficiente para caracterizar, de forma mais completa, a forragem da pastagem diferida, já que a mesma massa de forragem total pode ter composição morfológica, densidade volumétrica e valor nutritivo bastante distintos. Nesse sentido, Mannetje \& Ebersohn (1980) sugeriram que nos trópicos, onde as gramíneas acumulam grande quantidade de material morto durante a estação seca, a relação entre forragem disponível e consumo aplica-se apenas à fração verde do pasto. Neste trabalho, o aumento da massa de forragem verde elevou o desempenho animal em pastagens diferidas (Ano 1: $\hat{\mathrm{Y}}=0,2965+0,0000605 \mathrm{x}, \mathrm{r}^{2}=0,40, \mathrm{P}<0,01$; Ano 2: $\left.\hat{\mathrm{Y}}=-0,3329+0,0002721 \mathrm{x}, \mathrm{r}^{2}=0,77, \mathrm{P}<0,01\right)$.

No ano 1 , os valores de ganho de peso médio diários de todo o período de pastejo foram 0,634; 0,544; 0,695 e $0,600 \mathrm{~kg} /$ animal.dia em pastagens diferidas por 103, 121 , 146 e 163 dias, respectivamente. No ano 2, o ganho de peso ao longo de todo o período de pastejo nos animais mantidos nas pastagens diferidas por 73, 103, 131 e 163 dias correspondeu a 0,692; 0,518; 0,390 e 0,445 kg/animal.dia. Nesse ano, houve variação de até 0,302 kg/animal.dia em resposta aos períodos de diferimento da pastagem, mesmo com o consumo médio de suplemento estável em todas as pastagens diferidas. Esses resultados indicam que o mesmo tipo e quantidade de suplemento pode gerar 
desempenho animal diferente caso existam diferenças na qualidade e na quantidade de forragem produzida via diferimento da pastagem.

Ressalta-se que o desempenho dos bovinos mantidos em todas as pastagens diferidas foi elevado, uma vez que a suplementação utilizada nesse experimento foi idealizada para que os bovinos expressassem desempenho médio diário moderado, de aproximadamente 250 g por animal. O aumento do ganho médio diário dos animais em pastagens diferidas e suplementadas de capim-braquiária foi obtido com o período de diferimento do pasto de 73 dias.

O ganho de peso médio diário dos animais foi o único determinante da produção animal por unidade de área (GPA), já que a taxa de lotação inicial foi a mesma em todas as unidades experimentais. No ano 1, o ganho médio de peso durante todo o período de pastejo e em todas as pastagens diferidas foi igual 4,63 kg/ha.dia de peso animal, porém esta média decresceu de forma linear $(\mathrm{P}<0,01)$ durante o período de utilização das pastagens (Tabela 5). No ano 2, em pastagens diferidas por 73, 103, 131 e 163 dias, a média de todo o período de pastejo foi de 4,87; 4,69; 2,69 e 3,30 kg/ha.dia e a equação que melhor se ajustou aos dados incluiu os efeitos negativos e lineares dos períodos de diferimento $(\mathrm{P}<0,05)$ e de pastejo $(\mathrm{P}<0,01)$ (Tabela 5$)$. No ano 2 , os animais mantidos em pastagens diferidas por menor período (73 dias) tiveram melhor desempenho, o que resultou em maior produção animal por área. No entanto, durante o período de utilização das pastagens diferidas, o desempenho animal decresceu e, consequentemente, a produção animal por área diminui tanto no ano 1 quanto no ano 2 .

\section{Conclusões}

Variações na condição do clima entre anos influenciam a produção de forragem diferida. Na região de Viçosa, o desempenho de bovinos em recria mantidos em pastagens diferidas é melhor quando o pasto adubado e suplementado de Brachiaria decumbens cv. Basilisk é diferido por cerca de 70 dias e utilizado a partir do início do mês de julho.

\section{Literatura Citada}

CARVALHO, P.C.F.; RIBEIRO FILHO, H.M.N.; POLI, C.H.E.C. et al. Importância da estrutura da pastagem na ingestão e seleção de dietas pelo animal em pastejo. In: REUNIÃO ANUAL DA SOCIEDADE BRASILEIRA DE ZOOTECNIA, 38., 2001, Piracicaba. Anais... Piracicaba: Sociedade Brasileira de Zootecnia, 2001. p.883-871.
EUCLIDES, V.P.B. Produção intensiva de carne bovina em pasto. In: SIMPÓSIO DE PRODUÇÃO DE GADO DE CORTE, 2. 2001, Viçosa, MG. Anais... Viçosa, MG: Universidade Federal de Viçosa, 2001. p.55-82.

EUCLIDES, V.P.B.; EUCLIDES FILHO, K. Avaliação de forrageiras sob pastejo. In: SIMPÓSIO SOBRE AVALIAÇÃO DE PASTAGENS COM ANIMAIS, 1997, Maringá. Anais... Maringá: Universidade Estadual de Maringá, 1997. p.85-111.

EUCLIDES, V.P.B.; EUCLIDES FILHO, K.; ARRUDA, Z.J. et al. Desempenho de novilhos em pastagens de Brachiaria decumbens submetidos a diferentes regimes alimentares. Revista Brasileira de Zootecnia, v.27, n.2, p.246-254, 1998.

EUCLIDES, V.P.B.; MACEDO, M.C.M.; OLIVEIRA, M.P. Avaliação de diferentes métodos de amostragens (para estimar o valor nutritivo de forragens) sob pastejo. Revista da Sociedade Brasileira de Zootecnia, v.21, n.4, p.691-702, 1992.

EUCLIDES, V.P.B.; MEDEIROS, S.R. Suplementação animal em pastagens e seu impacto na utilização da pastagem. In: SIMPÓSIO SOBRE MANEJO DA PASTAGEM. 22., 2005, Piracicaba. Anais ... Piracicaba: Fundação de Estudos Agrários Luiz de Queiroz, 2005. p.33-70.

EUCLIDES, V.P.B.; VALLE, C.B.; SILVA, J.M. et al. Avaliação de forrageiras tropicais manejadas para produção de feno-em-pé. Pesquisa Agropecuária Brasileira, v.25, n.1, p.63-68, 1990.

GOMES JR., P.; PAULINO, M.F.; DETMANN, E. et al. Desempenho de novilhos mestiços na fase de crescimento suplementados durante a época seca. Revista Brasileira de Zootecnia, v.31, n.1, p.139-147, 2002.

LAZZARINI, I.; DETMANN, E.; SAMPAIO, C.B. et al. Dinâmica de degradação ruminal in situ da fibra em detergente neutro em bovinos alimentados com forragem de baixa qualidade suplementados com níveis crescentes de compostos nitrogenados. In: REUNIÃO ANUAL DA SOCIEDADE BRASILEIRA DE ZOOTECNIA, 43., 2006, João Pessoa Anais... João Pessoa: Sociedade Brasileira de Zootecnia, 2006. (CD-ROM).

MANNETJE, L.T.; EBERSOHN, J.B. Relations between sward characteristics and animal production. Tropical Grasslands, v.14, p.273-280, 1980.

MORAES, E.H.B.K.; PAULINO, M.F.; ZERVOUDAKIS, J.T. et al. Avaliação qualitativa da pastagem diferida de Brachiaria decumbens Stapf., sob pastejo, no período da seca, por intermédio de três métodos de amostragem Revista Brasileira de Zootecnia, v.34, n.1, p.30-35, 2005.

PARSONS, A.J.; LEAFE, E.L.; COLLET, B. et al. The physiology of grass production under grazing. II. Photosynthesis, crop growth and animal intake of continuously-grazed swards. Journal of Applied Ecology, v.20, p.127-139, 1983.

PAULINO, M.F.P.; DETMANN, E.; VALADARES FILHO, S.C. Suplementação animal em pasto: energética ou protéica? In: SIMPÓSIO SOBRE MANEJO ESTRATÉGICO DA PAStagem, 3., 2006, Viçosa, MG. Anais... Viçosa, MG: Universidade Federal de Viçosa, 2006. p.359-392.

SANTOS, E.D.G.; PAULINO, M.F.; QUEIROZ, D.S. et al. Avaliação de pastagem diferida de Brachiaria decumbens Stapf. 2. Disponibilidade de forragem e desempenho animal durante a seca. Revista Brasileira de Zootecnia, v.33, n.1, p.214-224, 2004.

SILVA, D.J.; QUEIROZ, A.C. Análises de alimentos: métodos químicos e biológicos. 3.ed. Viçosa, MG: Editora UFV, 2002. 235p.

UNIVERSIDADE FEDERAL DE VIÇOSA - UFV. SAEG - Sistema de análises estatísticas e genéticas. Versão 8.1. Viçosa, MG: 2003. 142p. (Apostila).

Van SOEST, P.J. Nutritional ecology of the ruminant. 2.ed. Ithaca: Cornell University Press, 1994. 476p. 